\title{
O MÉDICO HIGIENISTA NA ESCOLA: AS ORIGENS HISTÓRICAS DA MEDICALIZAÇÃO DO FRACASSO ESCOLAR*
}

\author{
THE HIGIENIST DOCTOR IN THE SCHOOL: HISTORICAL ORIGINS OF THE \\ MEDICALIZATION OF SCHOOL FAILURE
}

Patrícia Carla Silva do Vale Zucoloto**

Zucoloto PCSd, Patto MHS. O médico higienista na escola: as origens históricas da medicalização do fracasso escolar. Rev Bras Crescimento Desenvolv Hum 2007 17(1):136-145.

\begin{abstract}
Resumo: A presente pesquisa teve como objetivo investigar a história das explicações das dificuldades de escolarização das crianças das classes populares, em especial a versão que patologiza o fenômeno, através da análise de conteúdo do discurso médico sobre as concepções de higiene pública e de higiene escolar e do papel do médico na escola nas teses inaugurais da Faculdade de Medicina da Bahia na segunda metade do século XIX. Foram submetidas a análise de conteúdo cinco teses que traziam a questão da higiene das escolas em seus títulos e compreendiam o período histórico de 1869 a 1898, ou seja, o período correspondente à passagem do Império para a República. Os resultados dessa análise foram objeto de uma análise contextual, ou seja, foi realizada a sua inserção no momento histórico em que foram produzidos, tendo em vista a interpretação do conteúdo levantado. Verificou-se que as origens históricas da patologização dos problemas de escolarização das crianças das classes populares estão na defesa da importância da medicina para a escola, importância da presença médica nesta instituição e na concepção preconceituosa de povo brasileiro, central nas teorias adotadas pelos médicos. Concluiu-se que nas primeiras teses médicas sobre instituições escolares estão presentes prescrições que vão se concretizar pouco mais tarde na história da educação brasileira, como é o caso da inspeção médica na escola. Trata-se da constituição de um discurso médico sobre a educação que vai ser aprofundado e concretizado em teorias e ações ao longo do século XX.
\end{abstract}

Palavras-chave: Saúde escolar. Higiene escolar. Psicologia escolar. História da psicologia. Fracasso escolar. Medicalização. Patologização.

\section{INTRODUÇÃO}

O presente artigo se refere à pesquisa acerca das origens históricas do discurso da medicalização do fracasso escolar das crianças das classes populares.

Para vários pesquisadores no campo da educação ${ }^{1-4}$, o fracasso escolar, que se refere às dificuldades de escolarização das crianças das classes populares, têm sua origem na baixa qualidade de ensino da escola pública brasileira, no descompromisso do Estado com a educação do povo, nas políticas públicas educacionais que são feitas de maneira autoritária e desrespeitam professores e alunos, no preconceito existente para com o aluno pobre e sua família, enfim na

Artigo baseado em parte da dissertação de mestrado da Profa. Ms Patrícia Carla Silva do Vale Zucoloto realizada sob orientação da Profa. Dra. Maria Helena Souza Patto, apresentada ao Programa de Pós-graduação em Psicologia Escolar e do Desenvolvimento Humano do Instituto de Psicologia da Universidade de São Paulo.

** Profa. Substituta do Departamento de Psicologia da Faculdade de Filosofia e Ciências Humanas da Universidade Federal da Bahia (UFBA). Rua Cael, 113. Apto. 102. Acupe de Brotas. CEP: 40290-490. Salvador -BA. E-mail: patriciavz@ig.com.br. 
reprodução no cotidiano da escola dos conflitos inerentes à sociedade de classes, através de práticas e relações escolares que produzem as dificuldades de escolarização.

Tendo como pressuposto que a escola é uma instituição social que reproduz o conflito de classes da sociedade que a inclui e, desse modo, a compreensão das relações escola-sociedade de classes é o pano de fundo que permite um outro entendimento do que se passa nas escolas públicas de ensino fundamental: a sua dimensão política ${ }^{1}$. Parte-se, portanto, de uma postura crítica à psicologia que desconhece a realidade escolar e atribui a causa dos problemas de escolarização às crianças e suas famílias, explicando o fracasso escolar como consequiência de deficiências biopsicológicas individuais.

A história das explicações do fracasso escolar tem demonstrado a relação entre o discurso científico que explica o fenômeno e a ideologia dominante, de acordo com a qual só obtêm sucesso os mais aptos, os mais capazes, culpando os alunos pobres e suas famílias, justificando assim a desigualdade social e ignorando os determinantes escolares e políticos das dificuldades de escolarização ${ }^{1}$. Dentre as explicações para o fracasso escolar, se destacam aquelas que atribuem patologias às crianças que não aprendem ou não se comportam conforme a expectativa da escola: as explicações medicalizantes ou patologizantes.

Medicalizar o fracasso escolar é interpretar o desempenho escolar do aluno que contraria aquilo que a instituição espera dele em termos de comportamento ou de rendimento como sintoma de uma doença localizada no indivíduo, cujas causas devem ser diagnosticadas.

A perspectiva da medicalização do fracasso escolar persiste hoje no cotidiano da escola e atribui patologias às crianças das classes populares com dificuldades de escolarização, culpabilizando-as por suas dificuldades, a despeito de pesquisas $^{1,4-6}$ que põem em questão as relações causais entre distúrbios físicos e psicológicos, de um lado, e rendimento escolar, de outro, e que, colocando o foco nos fatores intra-escolares e dando voz às crianças provenientes das classes populares, mostram que elas são, em sua grande maioria, crianças capazes de aprender.
Profissionais como psicólogos, fonoaudiólogos, psicopedagogos, entre outros, adotaram o modelo médico, o que levou autores como Collares e Moysés ${ }^{2}$ a sugerirem a substituição do termo "medicalização" por outro mais abrangente, qual seja, "patologização" das dificuldades de escolarização.

Moysés ${ }^{4}$ refere-se a duas versões principais da patologização das dificuldades de escolarização que permanecem até hoje: o fracasso escolar considerado como conseqüência da desnutrição, o que é atribuído mais freqüentemente às crianças das classes populares e o fracasso escolar considerado como resultado da existência de disfunções neurológicas, tais como os distúrbios de aprendizagem, a hiperatividade, a disfunção cerebral mínima, a dislexia.

Collares e Moysés ${ }^{2}$ apresentam resultados de pesquisas que invalidam a relação de causalidade entre desnutrição e fracasso escolar e que podem ser resumidos em dois argumentos contrários a esta crença: as crianças que chegam às escolas públicas são portadoras de desnutrição leve, de primeiro grau, sem alterações no cérebro e em sua capacidade de aprender, por outro lado, a alfabetização é um processo que requer o uso das funções intelectuais superiores simples diante do potencial cognitivo do ser humano.

Com relação às "disfunções neurológicas" ou "distúrbios de aprendizagem", essas autoras demonstram que há uma longa trajetória de mitos, estórias criadas, fatos reais que são perdidos ou omitidos naquilo que denominam a história real e não-contada dos "distúrbios de aprendizagem". Questionam a existência desses "distúrbios" pela falta de comprovação científica, uma vez que argumentam que mesmo após cem anos de terem sido aventados pela primeira vez por um oftalmologista inglês, nada foi comprovado. Sendo essas pretensas doenças neurológicas jamais comprovadas devido à inexistência de critérios diagnósticos claros e precisos como exige a própria ciência neurológica, conservando conceitos vagos e abrangentes demais ${ }^{7}$ (p. 29). A patologização da educação consiste em um reducionismo biológico, que é explicar a situação e o destino de indivíduos e grupos através de suas características individuais, desse modo esconde os determinantes polí- 
ticos e pedagógicos do fracasso escolar, isentando de responsabilidades o sistema social vigente e a instituição escolar. Como decorrência dessa concepção, é o indivíduo o maior responsável por sua condição de vida e destino, as circunstâncias sociais e políticas teriam influência mínima.

A psicologia aderiu ao modelo médico de atendimento da queixa escolar e esta continua sendo a psicologia hegemônica, visto que a psicologia escolar tradicional ainda explica o fracasso escolar pela via da patologização e, desse modo, as explicações patologizantes do fracasso escolar continuam generalizadas na cultura escolar ${ }^{3}$. O discurso pregnante é o da deficiência ou da doença, os professores explicam que os alunos não aprendem porque são incapazes, deficientes ou doentes mentais ${ }^{2}$ Essas crenças dos professores geram a demanda por profissionais de saúde e tornam possíveis as condições para que a prática do psicólogo escolar na chave da psicopatologia continue a proliferar no âmbito do atendimento ao escolar. Diante da constatação que a medicalização do fracasso escolar está em pleno curso, surgiu a importância de investigar as origens históricas desta medicalização, perguntando-se sobre o papel que o discurso médico exerceu na construção dessa perspectiva de explicação das dificuldades de escolarização.

Lima $^{8}$ investigou a constituição histórica do discurso médico sobre a Saúde Escolar no estado de São Paulo e identifica a higiene escolar como primeiro constituinte desse discurso. A higiene escolar resultou, segundo esse autor, da interseção de três doutrinas:

"a da polícia médica, pela inspetoria das condições de saúde dos envolvidos com o ensino; a do sanitarismo, pela prescrição a respeito da salubridade dos locais de ensino; a da puericultura, pela difusão de regras de viver para professores e alunos e interferência em favor de uma pedagogia mais "fisiológica", isto é, mais adequada aos corpos escolares aos quais se aplicasse”. (p. 85)

Segundo Lima ${ }^{8}$, as primeiras interferências do Estado brasileiro em relação à questão da saúde nas escolas, a partir de 1850, foram tentativas de controle das diversas epidemias no Rio de Janeiro, e a escola era "apenas mais um lugar onde se reunia gente, que precisava ser fiscalizado, igualando-se a tantos outros locais onde isso acontecia, sem nenhuma primazia". (p. 88). Depois de 1900, é que a questão da higiene escolar ganha impulso, "culminando em sua institucionalização, na década de 10, em alguns estados brasileiros". (p. 88).

A origem de um discurso científico brasileiro mais independente dos setores hegemônicos e umbilicalmente ligados aos grupos agrários está no século XIX, de acordo com Schwarcz $(1993)^{14}$. Com a transferência da Corte portuguesa para o Brasil em 1808, foram criadas instituições culturais como as Faculdades de Medicina da Bahia e do Rio de Janeiro, as Faculdades de Direito em Pernambuco e em São Paulo, os Institutos Históricos e Geográficos e os Museus Etnográficos. Essas instituições possibilitaram a reunião dos primeiros cientistas brasileiros, leitores da produção científica européia, principalmente. Dentre esses cientistas, destacaram-se os médicos e o papel que a medicina desempenhou na sociedade brasileira na segunda metade do século XIX e no período da $1^{\mathrm{a}}$ República.

Gondra ${ }^{9}$ afirma que, na segunda metade do século XIX, a medicina tem sua órbita de interesse e competência ampliada, e o campo educacional emerge como campo conformado pelo discurso médico, uma vez que os médicos passam a definir regras para a organização e funcionamento da educação escolar.

Não há consenso, porém, entre historiadores da medicina e da educação sobre a presença efetiva dos médicos no corpo social durante o Império. Gondra ${ }^{9}$ e Freire Costa ${ }^{10}$ defendem que a presença médica na sociedade com esse objetivo de higienização social teria ocorrido no Império, portanto no século XIX. Por sua vez, Lima ${ }^{8}$, Stephanou ${ }^{11}$ e Patto ${ }^{12}$ afirmam que apenas no século XX teve início a inserção efetiva dos médicos na sociedade brasileira.

Todos os autores concordam, por outro lado, que ao ampliar os espaços de sua competência, a medicina gerou o fenômeno descrito como medicalização da sociedade, embora discordem quanto ao período em que se dá a presença dos médicos na gestão social. 
A medicalização da sociedade brasileira, de acordo com Freire Costa ${ }^{10}$, refere-se ao fato de que a Medicina e o Estado firmaram um compromisso de higienização das cidades e das populações, pois o Estado reconheceu que a ordem e o progresso sociais dependiam da higienização destas.

Os médicos, influenciados pela literatura européia, voltaram-se para a realidade da falta de higiene urbana e começaram a tratá-la em teses apresentadas às Faculdades de Medicina a partir de meados do século XIX. É neste contexto que surgem as teses de doutoramento defendidas nas Faculdades de Medicina, tendo como tema a higiene escolar.

A partir do estudo das teses sobre higiene dos colégios da Faculdade de Medicina do Rio de Janeiro, que tratavam de estabelecimentos de ensino que recebiam os filhos da elite, nos quais os alunos passavam a viver longe de suas famílias, Freire $\operatorname{Costa}^{10}$ concluiu que a estratégia de distanciamento do jovem do seu núcleo familiar fazia parte da apropriação médica da infância e da desqualificação das famílias coloniais, correspondendo à estratégia de medicalização do espaço urbano. (p. 180).

Gondra ${ }^{13}$ investigou as representações médicas acerca da educação e concluiu que um determinado modelo de organização escolar foi gestado no interior da ordem médica no século XIX, baseando-se em diversas fontes ${ }^{+}$, dentre as quais se destacam as teses médicas do Rio de Janeiro que abordam questões educacionais. A partir da sua análise, afirma que a educação estava ligada ao projeto civilizatório ocidental, pois para os médicos higienistas era necessário formar o homem, dominando a natureza na qual se encontrava inscrito e domando a sua própria natureza. Evidencia que a educação era a medida e o remédio para o objetivo de "instaurar uma ordem civilizada nos trópicos". (p. 410). Constata a presença do interesse privilegiado dos médicos pela questão educacional com o objetivo de que através da educação poderia ser produzido um homem e uma sociedade regenerados. A idéia de regeneração do povo brasileiro através da educação em uma escola higiênica diz respeito à influência das "teorias" raciais no pensamento médico a partir de 1870. Essas "teorias" (darwinismo social e evolucionismo) procuravam explicar as desigualdades sociais como desigualdades naturais, decorrentes de diferenças biológicas entre as raças e coube aos intelectuais brasileiros uma interpretação própria dessas "teorias". (cf. ${ }^{14}$ ).

Com o objetivo de dar continuidade à investigação das origens históricas e à compreensão das condições de produção dessa versão medicalizante da escola, que está na origem da patologização dos problemas de escolarização, em geral, e das crianças das classes populares, em particular, a presente pesquisa procurou analisar o discurso médico sobre a escola nas teses inaugurais da Faculdade de Medicina da Bahia na segunda metade do século XIX. Esse artigo se deterá sobre os objetivos específicos de investigar, nas teses selecionadas, as concepções de higiene pública e de higiene escolar e do papel do médico na escola.

\section{MÉTODO}

Tendo esse objetivo, fomos às origens da ciência médica brasileira, mais precisamente, garimpamos os primeiros documentos aqui produzidos sobre a escola brasileira no meio médico, os quais foram as teses inaugurais para obtenção do grau de doutor nos cursos médicos da Bahia e Rio de Janeiro, particularmente aquelas que tratavam da higiene das escolas.

Escolhemos trabalhar com as teses inaugurais da Faculdade de Medicina da Bahia (FAMEB) porque as teses sobre higiene escolar presentes na Faculdade de Medicina do Rio de

Gondra $^{13}$ baseou-se na leitura da "legislação médica no século XIX, das memórias históricas das instituições e de alguns personagens do campo médico, de incursões tópicas em relatórios de Ministros dos Negócios do Império e de professores, relatos de viajantes estrangeiros, jornais, boletins e fontes literárias, bem como do levantamento exaustivo das teses defendidas junto à FMRJ no período referido, tendo sido este último, seguido de uma dupla seleção, sendo a primeira recortada pelo critério de uma medicina preocupada com aspectos sociais, e a segunda, de uma medicina preocupada com aspectos educacionais.” (p. 408). 
Janeiro abordavam a higiene dos colégios destinada aos filhos das elites brasileiras e nosso interesse era pela escola pública e além do mais, estas já haviam sido analisadas por Freire Costa $^{10}$ e Gondra ${ }^{9}$. Outro fator que contribuiu para esta escolha foi que havia um grande interesse pela higiene pública por parte dos médicos baianos, como observou Schwarcz ${ }^{14}$, e desse interesse surgiram teses de doutoramento e um predomínio de artigos sobre esse tema na revista da Faculdade de Medicina da Bahia: a Gazeta Medica da Bahia.

A análise das teses teve como referência o método de análise de conteúdo proposto por Bardin ${ }^{15}$, tendo seguido duas etapas: a pré-análise, que compreende a preparação do material a ser analisado, e a análise de conteúdo propriamente dita.

Foram selecionadas dentre as teses da FAMEB aquelas que portavam em seus títulos a referência explícita a questão da higiene das escolas constituindo assim o corpus a ser analisado, de acordo com os critérios de exaustividade, segundo a qual tivemos em conta todos os documentos desses acervos e de pertinência, de acordo com a qual foram selecionados os documentos adequados ao objetivo da análise.

Dez teses foram selecionadas inicialmente e compreendiam o extenso período de 1869 a 1930. Dado o longo período histórico abrangido, optouse por trabalhar com as cinco primeiras, correspondendo ao período de 1869 a 1898 , a fim de melhor compreender as idéias produzidas no período de passagem do Império para a República.

Foram analisadas as seguintes teses de doutoramento da Faculdade de Medicina da Bahia: Silva ${ }^{16}$; Collet ${ }^{17}$; Marques ${ }^{18}$; Lobo $^{19}$ e Patury ${ }^{20}$.

\section{RESULTADOS}

A análise das teses nos conduziu à organização do conteúdo concernente às concepções presentes nas mesmas em dez aspectos referentes aos objetivos específicos, dentre os quais apresentaremos nesse artigo as concepções de higiene pública e de higiene escolar e as concepções do papel do médico na escola (o médico higienista escolar e a inspeção médica na escola).
As cinco teses compreendem o período que se estende de 1869 a 1898 , sendo que da $1^{a}$ para a $2^{\mathrm{a}}$ tese, há um intervalo de 16 anos (1869 para 1885). As três primeiras localizam-se no período do Segundo Império. A $4^{\mathrm{a}}$ e a $5^{\mathrm{a}}(1895 ; 1898)$ correspondem ao início da Primeira República. O discurso presente nas teses carrega a influência das questões do contexto social, político e econômico de cada época.

As teses tratam predominantemente das escolas primárias destinadas ao ensino público, porém algumas também se referem a colégios internos e a primeira tese fala exclusivamente desses colégios pagos destinados aos filhos da elite econômica. Essa primeira tese foi mantida no corpo de documentos a ser analisado porque o fato de não tratar das escolas públicas pode ser entendido como evidência de que faltavam de fato escolas para o povo, como é demonstrado na literatura sobre a época. ${ }^{21,22}$.

O discurso nas teses é articulado do seguinte modo: primeiro procura-se definir o tema escolhido e justificar a sua importância; em seguida, o próprio tema é desenvolvido e durante a apresentação das prescrições higiênicas, a maior parte dos autores procura, por comparação, refletir sobre a realidade da educação brasileira, particularmente a baiana.

As teses circulam por diversos temas relacionados à higiene das escolas. Os temas abrangem desde prescrições higiênicas quanto à escolha do terreno e à construção do prédio escolar até a concepção de educação, de escola, de método de ensino, do papel do professor e do papel da família e do Estado. Abordam predominantemente aspectos da estrutura física e do funcionamento das escolas, à luz das exigências higiênicas a serem seguidas.

Descreveremos a seguir as concepções de higiene pública, de higiene escolar e do papel do médico higienista na escola presentes nas teses.

\section{As concepções de higiene pública e de higiene escolar}

A higiene escolar é contextualizada como pertencente ao tema maior da higiene pública ou 
higiene geral. A concepção de higiene geral está presente nas teses de 1869, 1885 e 1898; as demais definem exclusivamente a higiene escolar ou higiene pedagógica.

Na tese de 1869, a higiene pública é definida como prevenção de doenças. Na tese de 1885 , comparece também a concepção de higiene como preservação da saúde do corpo e do espírito. A tese de 1898, no entanto, concebe a higiene como a "magna questão" que soluciona o "problema social", mas não o explicita e defende que sua aplicação seja considerada urgente no Brasil.

Vários são os nomes dados a higiene escolar nas teses: desde "hygiene dos colégios", na tese de 1869 até "hygiene pedagógica", na tese de 1886; passando pelas teses de 1885, 1895 e 1898, nas quais é denominada "hygiene escholar".

Nas duas primeiras teses $(1869,1885)$, a higiene é uma necessidade das escolas em geral, a fim de evitar o adoecimento das crianças. É, portanto, uma preocupação com a saúde pública, com a prevenção de doenças, com a propagação de epidemias, o que se justifica na época, levando em consideração a realidade baiana.

A partir da terceira tese, de Marques, no ano de $1886^{18}$, a concepção de higiene escolar se dirige para o objetivo de elevar a nação brasileira à altura das nações civilizadas através da escola higiênica, desse modo a higiene escolar não é mais uma preocupação vaga com a atenção ao bemestar e à formação da geração nascente e com o futuro do país. Surge uma preocupação concreta com as crianças e jovens considerados como o "gérmen do futuro cidadão" e, portanto, também como a força motriz de todo progresso da nação. Esta preocupação vai se revelar no projeto de escola higiênica.

De acordo com Lobo ${ }^{19}$, a escola higiênica pode resolver o "mais difficil problema social: o de preparar a geração que surge para com patriotismo corrigir os erros do presente, que não são poucos, e elevar a patria à altura que ella merece no quadro das nações civilisadas". (p. 1).

As teses afirmam a responsabilidade da escola de criar cidadãos vigorosos e denunciam que no Brasil ocorre o contrário: a escola cria seres deformados e raquíticos, pois não obedece às prescrições higiênicas.
Comparece em algumas teses uma crítica às escolas baianas e mais, à situação em que a educação do povo se encontra no país.

Marques ${ }^{18}$ defende que o movimento pela higiene escolar produzirá uma revolução social, definida como o "interesse pela educação pública carente das leis hygienicas". (p. 37)

Em 1898, na quinta tese, a importância da higiene escolar para o Brasil refere-se ao intuito de aperfeiçoamento da raça, denotando a influência das "teorias" raciais no pensamento médico. São objetivos da higiene escolar, de acordo com Patury ${ }^{20}$ : regenerar o caráter, combater os vícios, nulificar os interesses individuais e transformá-los em interesses coletivos, incutir o cumprimento do dever e o amor ao trabalho, criar o sentimento nacional, aperfeiçoar a raça. Afirma que para a construção de uma pátria feliz, forte e instruída, é preciso que se tenha um povo bem educado.

\section{As concepções do papel do médico na escola: $o$ médico higienista escolar e a inspeção médica na escola}

Enquanto na primeira tese, comparece uma menção geral da relação da medicina com a escola, a partir da segunda tese, por exemplo, em Collet, em $1885^{17}$, defende-se a importância de uma fiscalização rigorosa nas escolas para prevenir a eclosão de doenças, que são geradas pela negligência para com a higiene. Aparece também a denúncia da falta da inspeção médica nas escolas e colégios no Brasil.

A partir da quarta tese, em 1895, a figura do médico inspetor escolar vai ter seu papel definido: este deve atentar para a prevenção e controle de doenças e "perversões" nos alunos, através da verificação das condições higiênicas das escolas pela avaliação dos seus aspectos estruturais e funcionais e das condições físicas dos alunos.

O médico inspetor escolar deve ser formado através do estudo de diversos saberes, dentre eles a organização do trabalho pedagógico.

A idéia de fiscalização das condições escolares inclui a atenção a aspectos morais, desde a moralidade dos professores e "dirigentes" da "casa de educação" até à condenação do uso de castigos sem moderação ou prudência por parte 
dos mestres, como também a condenação da ocorrência do "onanismo" e da pederastia entre os discípulos. Por exemplo: Silva, em $1869^{16} \mathrm{e}$ Collet, em $1885^{17}$ recomendam que haja vigilância por parte dos professores em relação aos alunos para evitar que ocorra o "onanismo" ou "hábitos solitários" e a pederastia, também denominada "actos de immoralidade" que comprometeriam a saúde dos alunos.

\section{DISCUSSÃO}

As cinco teses inaugurais da Faculdade de Medicina da Bahia sobre a higiene das escolas e colégios configuram um momento de constituição de um discurso médico sobre a educação e sobre a escola centrado numa concepção de escola como instituição higiênica.

Nesse momento da história brasileira, os médicos viam as escolas como lugares coletivos que contribuíam para a gênese e a disseminação de doenças que assolavam as cidades brasileiras. E, de fato, as condições sanitárias e higiênicas da Bahia eram precárias: em Salvador, por exemplo, não havia rede de esgotos e a população ficava sujeita a moléstias infecto-contagiosas e a epidemias. Tavares ${ }^{23}$ relata que as mais graves epidemias foram as de febre amarela e cólera dos anos de 1850 e 1855, as quais fizeram milhares de vítimas na Bahia. Estes eram problemas de higiene pública para os quais os médicos brasileiros não estavam indiferentes.

É verdade também que, como apontam vários autores ${ }^{24,25}$ estava presente entre eles um forte desejo de serem europeus, ou seja, os nossos "homens de sciencia" participavam do que esses autores chamaram de "feitiço do transoceanismo" ou "bovarysmo". As teses analisadas repetem os mesmos conteúdos, como se os autores houvessem lido os mesmos manuais de higiene escolar, o que de fato se confirma no levantamento de autores e obras citadas. É vasta a literatura estrangeira referida e as teses são ricas em citações em língua estrangeira, principalmente de autores franceses. O discurso é constituído com base em trabalhos científicos realizados em outros países, embora já haja expressão do desejo de origi- nalidade. As críticas à imitação de idéias estrangeiras, no entanto, limitam-se a adaptações materiais, em vista das diferenças climáticas entre os países-modelo e o Brasil. Além disso, há referência a trabalhos nacionais, entre os quais se destacam os Pareceres de Rui Barbosa (18821883), segundo Patto (comunicação pessoal) estes textos referentes ao projeto educacional de Reforma do Ensino Primário e Secundário elaborados pelo então deputado baiano eram longos, detalhados e ricos de citações de trabalhos e experiências de autores europeus e norte-americanos. Por isso, esses documentos funcionaram como mediadores entre as idéias estrangeiras sobre educação e higiene escolar e os médicos brasileiros.

Essas teses veiculam um discurso normatizador, prescrevem um modelo ideal de escola de acordo com a ciência da higiene. Para que esse modelo se efetive, a higiene escolar precisa estar presente em todas as dimensões da escola: a estrutura física (localização, construção do prédio escolar, dimensão das salas de aula, cubagem do ar, dimensão das mobílias, etc.), as relações escolares e o próprio método de ensino. Nas minúcias das prescrições, encontra-se um desejo de controle absoluto. Ou seja, um projeto inovador de disciplinamento do corpo social por meio da prevenção de desvios físicos, intelectuais e morais de crianças e adolescentes.

Os médicos denunciam que o maior problema das escolas brasileiras era sua inadequação higiênica. As recomendações referem-se principalmente a prevenção das doenças, objetivo que se tornou obsessão da medicina depois das descobertas de Pasteur e Koch.

A primeira tese trata da colaboração que a medicina pode dar à escola enquanto instituição abstrata e portanto, descontextualizado da realidade baiana. Mas, a partir da segunda a situação das escolas brasileiras começa a ser mencionada para tornar-se tema a partir da terceira. Nota-se, então, todo um empenho em prescrever medidas de higienização das escolas alheio à realidade brasileira de falta de escolas e de uma política educacional, de professores mal remunerados e mal formados e de descaso do Estado brasileiro para com a educação do povo.

No Império, a educação pública foi rele- 
gada ao plano das leis apenas, pois na prática muito pouco foi realizado ${ }^{21}$. Havia poucas escolas de ensino elementar no Brasil, portanto havia uma grande massa analfabeta. De acordo com as estatísticas citadas por Lourenço Filho, "as escolas primárias, em número de 15.561, reuniam, em 1878, 175 mil alunos". Da população livre em todo o país, cerca de nove milhões de habitantes, os alunos representavam apenas $2 \%$ desta população; o recenseamento de 1870 registrara um índice de analfabetos de $78 \%$ na população de 15 anos e mais ${ }^{21}$ (p. 382).

Como se sabe, um sistema educacional unificado no Brasil só começaria a tomar corpo mais de meio século depois, quando da criação do primeiro Ministério de Educação em 1930.

Podem ser localizadas as origens históricas da medicalização dos problemas de escolarização das crianças das classes populares na defesa da importância da medicina para a escola, importância da presença médica nesta instituição e na concepção preconceituosa de povo brasileiro, central nas teorias adotadas pelos médicos.

Nessas teses médicas, a concepção de povo brasileiro está perpassada pelas "teorias raciais", o que torna possível afirmar que a desvalorização dos integrantes das classes populares está na origem da crença de que os pobres e não-brancos são, em geral, incapazes de escolarização. No discurso médico e educacional, poucos anos depois da produção dessas teses, o uso de termos negativos para designá-los e para explicar sua exclusão escolar e sua inclusão social marginal já está instalado:

Nos documentos oficiais, na imprensa, nos relatórios e pareceres dos especialistas vai-se constituindo um vasto rol de termos infamantes para designar os pobres: degenerados, anormais, selvagens, ignorantes, incivilizados, feios, desordeiros, rudes, grevistas, incapazes, preguiçosos, boêmios, anarquistas, brutos, irresponsáveis, desregrados, perniciosos, bêbados, farristas, decaídos, nocivos, arruaceiros, desocupados, marginais, deletérios, animalescos, simiescos, mediocres, sujos, libertinos, trapaceiros, parasitas, vadios, viciados, ladrões, criminosos. $\left({ }^{26}\right.$, p. 184)
Nas primeiras teses médicas sobre instituições escolares, estão presentes prescrições que vão se concretizar pouco mais tarde na história da educação brasileira, como é o caso da inspeção médica na escola. Ou seja, trata-se da constituição de um discurso médico sobre a educação que vai ser aprofundado e concretizado em teorias e ações ao longo do século XX. Exemplo disto são os discursos do médico Miguel Couto, presidente perpétuo desde 1913 da Academia Nacional de Medicina, nos quais a educação é definida como o problema nacional por excelência. A criação do Serviço de Inspeção Médica Escolar da Cidade do Rio de Janeiro em 1910, cujo primeiro diretor foi Moncorvo Filho, médico do Instituto de Proteção e Assistência à Infância do Rio de Janeiro, fundado em $1889^{8}$. Em São Paulo, já em 1890 teve início a Inspeção Médica Escolar. Porém, o Serviço de Inspeção Médica Escolar, ligado ao governo do estado de São Paulo, só foi criado em 1911. Nos estados da Bahia, Pernambuco e Minas Gerais foram criados serviços semelhantes em 1913, no Paraná e em Santa Catarina em $1918^{8}$.

Os médicos começam a marcar presença não só nas escolas públicas, mas no corpo docente das Escolas Normais realizando a formação dos profissionais da educação ${ }^{1}$. Na década de 30 , o médico e antropólogo Arthur Ramos, discípulo de Nina Rodrigues na Faculdade de Medicina da Bahia, criou clínicas e centros de higiene mental escolar e produziu o primeiro livro sobre problemas de aprendizagem escolar: A creança proble$m a$ (1939), dando relevo à questão das crianças que "não aprendiam" que vinha sendo tratada desde a década de 20 pela classe médica, na perspectiva da patologização.

Patto $^{1}$ afirma que no início do século XX a determinação dos "anormais" e sua segregação já era uma prática social de competência médica e evidencia que muitos médicos "tiveram uma participação decisiva na constituição teórica e instrumental da psicologia educacional, direcionando-a, para a aquisição de uma identidade baseada no modelo médico." (p. 63)

De acordo com Moysés ${ }^{4}$, a Medicina exerceu um papel fundamental na construção das doenças do não-aprender, criando a demanda por 
serviços de saúde especializados e firmando-se como instituição competente e responsável pela resolução de problemas.

Segundo esta médica pediatra e pesquisadora, não foi a ampliação do acesso à escola pública das crianças das classes populares que gerou a medicalização da aprendizagem e da nãoaprendizagem, pois a medicina afirmava $a$ priori que "as crianças das classes trabalhadoras são mais debilitadas, mal nutridas, doentes etc. e, portanto, irão apresentar problemas na escolarização, a menos que haja uma atuação médica". (p. 299). Sendo assim, as queixas escolares em relação às crianças da rede pública de ensino são "problemas, em sua grande maioria, decorrentes da esfera temporal, política e social em que vivem", ou seja, referentes a "sua inserção social e da decorrente qualidade de suas vidas, (...) de sua historicidade, como homens". (p. 126).

Esta patologização das dificuldades de escolarização persiste até hoje, como já falamos e teve início nas primeiras aproximações da medicina com a educação escolar e na defesa da presença médica para fiscalizar e garantir a saúde dos educandos.

\section{AGRADECIMENTOS}

Agradeço à professora Maria Helena S. Patto pela orientação e às professoras Maria Aparecida A. Moysés, Marina Massimi e a Sandra M. Sawaya pela interlocução. Agradeço ainda às professoras Dinorah Castro e Nádia Rocha pela introdução à riqueza das teses médicas da Faculdade de Medicina da Bahia. A Rodolfo Teixeira, médico e pesquisador da História da Medicina da Bahia, pelas valiosas referências históricas. À Zilda, aos funcionários do Memorial da Medicina e da Biblioteca Pública da Bahia, a Caio César Tourinho e Antônio do Vale Filho pela solicitude em auxiliar os pesquisadores. A Rodrigo Barban Zucoloto pelo incentivo à produção científica. A Capes pelo financiamento desta pesquisa.

\begin{abstract}
The present research study aimed to investigate the historical origin of explanations for school difficulties of children of low socioeconomic status, specially the version that gives a pathologic meaning to the phenomenon, through the analysis of the medical discourse about the definitions of public hygiene and school hygiene and of the doctor's role in the school. The actual research investigated the medical discourse about the school in five Inaugural Theses of the School of Medicine of Bahia under the theme "Hygiene of schools". The theses were from the historical period comprehended between 1869 and 1898, which corresponds to Brazil's transition from an Empire to a Republic. A contextual analysis of the results was carried out by means of their insertion into the historical period in which they were produced. The analysis investigated the theoretical and practical bases of these thoughts. The analysis of discourse content was performed using Bardin (1977)'s method of content analysis. It could be verified that the historical origin of the medical concept of school problems faced by children of low socioeconomic status is in the defense of the importance of the medical presence in the school and in the prejudiced view of the Brazilian people that was adopted by the medical staff at that period. It was concluded from the five theses that ideas that will gain strength later in the history of Brazilian education, as the "medicalization" of school difficulties, are already there. This is the case of medical inspection in school, constituting a medical discourse about education that will be deepened and implemented by means of theories and actions throughout the $20^{\text {th }}$ century.
\end{abstract}

Key words: School health. School hygiene. School psychology. School difficulties. History of psychology. Medicalization. 


\section{REFERÊNCIAS}

1. Patto MHS. A produção do fracasso escolar: histórias de submissão e rebeldia. São Paulo: T.A. Queiroz; 1990.

2. Collares CAL, Moysés MAA. A transformação do espaço pedagógico em espaço clínico: a patologização da educação. In: Alves ML, coordenador. Cultura e saúde na escola. São Paulo: Fundação para o Desenvolvimento da Educação; 1994. p. 25-31.

3. Souza MPR, Machado AM, organizadores. Psicologia escolar: em busca de novos rumos. São Paulo: Casa do Psicólogo; 1997.

4. Moysés MAA. A institucionalização invisível: crianças que não-aprendem-na-escola [tese de livre-docência]. Campinas: Universidade Estadual de Campinas; 1998.

5. Goldenstein MS. A exclusão da escola de $1^{\circ}$ grau: a perspectiva dos excluídos. São Paulo: Fundação Carlos Chagas; 1986.

6. Machado AM. Reinventando a avaliação psicológica [tese]. São Paulo: Universidade de São Paulo; 1996.

7. Collares C, Moysés MAA. A história não contada dos distúrbios de aprendizagem. Cad CEDES. 1992;28:31-48.

8. Lima GZ. Saúde escolar e educação. São Paulo: Cortez; 1985.

9. Gondra JG. Silêncios na história da educação no império. In: Vidal DG, Gondra JG, Faria Filho LM, organizadores. Educação, modernidade e civilização: fontes e perspectivas de análises para a história da educação oitocentista. Belo Horizonte: Autêntica; 1998. p. 37-71.

10. Freire Costa J. Ordem médica e norma familiar. $3^{\text {a }}$ ed. Rio de Janeiro: Graal; 1989.

11. Stephanou M. Formar o cidadão física e moralmente: médicos, mestres e crianças na escola elementar. Educ Subj Poder. 1996;3(3):59-66.
12. Patto MHS. Teoremas e cataplasmas no Brasil monárquico: o caso da medicina social. Novos Estud CEBRAP. 1996;44:180-99.

13. Gondra JG. Artes de civilizar: medicina, higiene e educação escolar na corte imperial [tese]. São Paulo: Universidade de São Paulo; 2000.

14. Schwarcz LM. O espetáculo das raças: cientistas, instituições e questão racial no Brasil (1870-1930). São Paulo: Companhia das Letras; 1993.

15. Bardin L. Análise de conteúdo. Rio de Janeiro: Edições 70; 1977.

16. Silva FP. Hygiene dos collegios [tese]. Salvador: Faculdade de Medicina da Bahia; 1869.

17. Collet AG. Hygiene escholar [tese]. Salvador: Faculdade de Medicina da Bahia; 1885.

18. Marques UHM. Hygiene pedagógica [tese]. Salvador: Faculdade de Medicina da Bahia; 1886.

19. Lobo FCS. Apontamentos para o estudo da hygiene escholar [tese]. Salvador: Faculdade de Medicina da Bahia; 1895.

20. Patury JL. Hygiene escolar [tese]. Salvador: Faculdade de Medicina da Bahia; 1898.

21. Werebe MJG. A educação. In: Buarque de Holanda S, organizador. História geral da civilização brasileira. São Paulo: Difel; 1986.

22. Nunes AA. Educação na Bahia no século XIX: algumas considerações. Rev Inst Geogr Hist Bahia. 1997;93:165-203.

23. Tavares LHD. História da Bahia. $10^{\mathrm{a}}$ ed. São Paulo: UNESP; Salvador: EDUFBA; 2001.

24. Cruz Costa J. Pequena história da República. São Paulo: Braziliense: CNPq; 1988.

25. Buarque de Holanda S. Raízes do Brasil. 15a ed. Rio de Janeiro: José Olympio; 1982.

26. Patto MHS. Estado, ciência e política na Primeira República: a desqualificação dos pobres. Estud Av. 1999;35(13):167-98.

Recebido em 06/11/2006

Aprovado em 13/12/2006 